Jul 1st, 12:00 AM

\title{
Decision Making under Uncertainty in a Decision Support System for the Red River
}

Inge A. T. De Kort

Martijn J. Booij

Follow this and additional works at: https://scholarsarchive.byu.edu/iemssconference

De Kort, Inge A. T. and Booij, Martijn J., "Decision Making under Uncertainty in a Decision Support System for the Red River" (2004). International Congress on Environmental Modelling and Software. 216.

https://scholarsarchive.byu.edu/iemssconference/2004/all/216

This Event is brought to you for free and open access by the Civil and Environmental Engineering at BYU ScholarsArchive. It has been accepted for inclusion in International Congress on Environmental Modelling and Software by an authorized administrator of BYU ScholarsArchive. For more information, please contact scholarsarchive@byu.edu, ellen_amatangelo@byu.edu. 


\title{
Decision Making under Uncertainty in a Decision Support System for the Red River
}

\author{
Inge A.T. de Kort and Martijn J. Booij \\ Faculty of Engineering Technology, University of Twente, P.O. Box 217, 7500 AE Enschede, the Netherlands \\ (i.a.t.dekort@utwente.nl; m.j.booij@utwente.nl)
}

\begin{abstract}
Decision support systems (DSSs) are increasingly being used in water management for the evaluation of impacts of policy measures under different scenarios. The exact impacts generally are unknown and surrounded with considerable uncertainties. These uncertainties stem from natural randomness, uncertainty in data, models and parameters, and uncertainty about measures and scenarios. It may therefore be difficult to make a selection of measures relevant for a particular water management problem. In order to support policy makers to make a strategic selection between different measures in a DSS while taking uncertainty into account, a methodology for the ranking of measures has been developed. The methodology has been applied to a pilot DSS for flood control in the Red River basin in Vietnam and China. The decision variable is the total flood damage and possible flood reducing measures are dike heightening, reforestation and the construction of a retention basin. For illustrative purposes, only parameter uncertainty is taken into account. The methodology consists of a Monte Carlo uncertainty analysis employing Latin Hypercube Sampling and a ranking procedure based on the significance of the difference between output distributions for different measures. The significance is determined with the Student test for Gaussian distributions and with the non-parametric Wilcoxon test for non-Gaussian distributions. The results show Gaussian distributions for the flood damage in all situations. The mean flood damage in the base situation is about 2.2 billion US\$ for the year 1996 with a standard deviation due to parameter uncertainty of about 1 billion US\$. Selected applications of the measures reforestation, dike heightening and the construction of a retention basin reduce the flood damage with about 5, 55 and 300 million US\$ respectively. The construction of a retention basin significantly reduces flood damage in the Red River basin, while dike heightening and reforestation reduce flood damage, but not significantly.
\end{abstract}

Keywords: Decision support systems; Water management; Uncertainty; Ranking methodology; Red River

\section{INTRODUCTION}

Decision support systems (DSSs) are increasingly being used in water management for the evaluation of impacts of policy measures under different scenarios. The exact impacts generally are unknown and surrounded with considerable uncertainties. These uncertainties stem from natural randomness, uncertainty in data, models and parameters, and uncertainty about measures and scenarios. It may therefore be difficult to make a selection of measures relevant for a particular water management problem.

This paper describes a methodology for the ranking of measures in order to support policy makers to make a strategic selection between different measures in a DSS while taking uncertainty into account. The methodology is applied to a pilot DSS for flood control in the Red River basin in Vietnam and China. The decision variable is the total flood damage and possible flood reducing measures are dike heightening, reforestation and the construction of a retention basin. For illustrative purposes, only parameter uncertainty is taken into account.

\section{DESCRIPTION OF DSS}

\subsection{Introduction}

The DSS consists of a hydrological, hydraulic and socio-economic model. The hydrological model has a spatial resolution of $5 \mathrm{~km}$ for the complete river basin. The output of this model is input into the 
hydraulic model, which has a spatial resolution of 1 $\mathrm{km}$ for the deltaic part of the river basin. The output of the hydraulic model is input into the socioeconomic model. This latter model has a spatial resolution of both $1 \mathrm{~km}$ and $5 \mathrm{~km}$ (see Figure 1. ). The temporal resolution of the DSS is one day and the time period considered one year (1996). This year has been chosen, because it contains one of the major floods which have occurred in the river basin. The DSS is implemented in the GIS-based model environment PCRaster [Wesseling et al., 1996] as discussed in Booij [2003]. The three models are described in 2.2 and the flood control measures are considered in 2.3 .

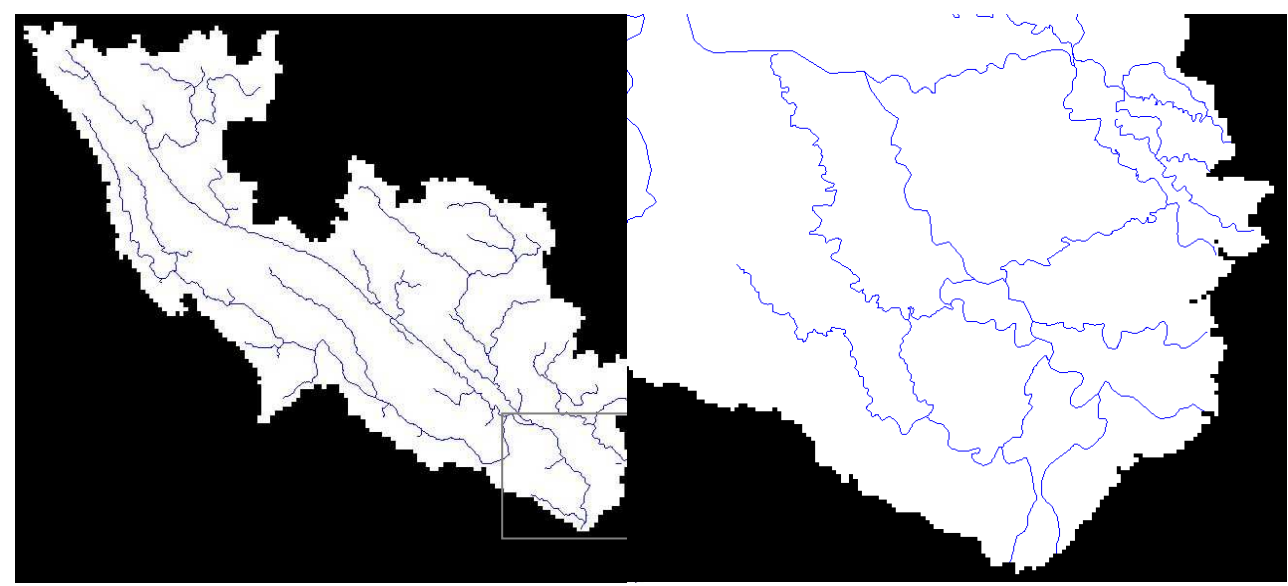

Figure 1. Red River basin at a spatial resolution of $5 \mathrm{~km}$ (left, extent of area $770 \mathrm{~km} \mathrm{x} 660 \mathrm{~km}$ ) and delta of the Red River basin at a spatial resolution of $1 \mathrm{~km}$ (right, extent of area $154 \mathrm{~km} \times 132 \mathrm{~km}$ ).

\subsection{DSS model components}

The hydrological model is based on the HBV model concepts [Bergström and Forsman, 1973]. The HBV model is a conceptual hydrological model and simulates basin discharge using precipitation and evapotranspiration as input. The relevant routines used are a precipitation routine representing rainfall, a soil moisture routine determining actual evapotranspiration, overland flow and subsurface flow, a fast flow routine representing storm flow, a slow flow routine representing subsurface flow and a transformation routine for flow delay and attenuation.

The simulated discharge serves as input into the hydraulic model. It is transformed into water depth using a stage-discharge relation derived from measured data. The water depth applies to the complete deltaic area. An additional water depth due to the tide is added to this water depth. The inundation depth in the flooded area is determined using this river water depth, the dike height and the elevation in the flooded area. A certain decrease of the inundation depth is assumed when in the flood wave is in its falling stage.

The socio-economic model determines with simple, linear functions the flood damage and incomes for different economic sectors. The flood damage is dependent on the simulated inundation pattern and the land use type, while the incomes are dependent on the economic sector (through prices, costs etc.) and the land use type. The decision variable is the total flood damage in the deltaic area of the Red River basin.

\subsection{Flood control measures}

The DSS can be used for the evaluation of impacts of policy measures under different scenarios. Three different measures are considered, namely dike heightening, reforestation and the construction of a retention basin. The impacts of these measures will be compared with the impacts in the base situation. The measures are briefly described below.

The dike system is represented by a constant dike height relative to mean sea level, which obviously is a simplification of reality. Moreover, it is assumed that the dike system is of good quality, which may not hold in reality. For example Nghia [2000] states that the overall dike system is outdated, poor in repair and vulnerable to erosion. The measure dike heightening is achieved by increasing the constant dike height with 1 meter. 
Reforestation is a sustainable flood control measure and supports retainment of water in the soil and prevents erosion. This is achieved by adapting the land use pattern in the DSS, which subsequently will change the soil moisture function in the hydrological model and the damage and income estimates in the socio-economic model. Forest is randomly attributed to areas in a certain elevation range and with some specific land use types in the base situation.

The construction of a retention basin is based on an existing retention basin. The main functions of the basin are flood control and power production. The water storage and release are dependent on several factors such as the inflow, the actual storage in the reservoir, the minimum and maximum storage and the maximum outflow. More details about the implementation of the reservoir in the DSS can be found in De Kort [2003].

\section{RED RIVER BASIN}

The Red River basin is situated in China and Vietnam and has a surface area of about 169000 $\mathrm{km}^{2}$. The delta covers about $15000 \mathrm{~km}^{2}$ and starts near Hanoi, the capital of Vietnam. The average annual precipitation strongly varies over the area between 700 and $4800 \mathrm{~mm}$. About $80 \%$ of the precipitation occurs in summer when the Southwest monsoon brings warm, moist air across in the IndoChinese peninsula. Most of the floods therefore occur in July and August. The average discharge of the Red River is about $3750 \mathrm{~m}^{3} / \mathrm{s}$ [Nghia, 2000].

Similar to elsewhere in Southeast Asia, there is a marked contrast between the isolated and sparsely populated mountains and the densely populated delta. The delta is a low lying area mainly used for the cultivation of rice (about $88 \%$ of the area) and has one of the highest population densities (over 1000 people per $\mathrm{km}^{2}$ ) in the world. The upstream, mountainous area is more forested (about $42 \%$ of the area) and grassland forms the transition zone between the forest and rice areas.

Daily precipitation and evapotranspiration data from 15 stations and daily discharge data from 5 stations are used in this analysis. Furthermore, elevation data from a global digital elevation model and land use data from a global land cover database are employed. The spatial resolutions are $1 \mathrm{~km}$ for both the elevation and land use data. This spatial resolution for elevation is assumed to be appropriate for inundation modelling taking into account the flatness of the study area and the research objective. Socio- economic data include incomes, agricultural yields and flood damage in general at a provincial level and on an annual basis. Further information about the Red River basin and the data resources can be found in Booij [2003] and De Kort [2003].

\section{RANKING METHODOLOGY}

\subsection{Introduction}

A methodology for the ranking of measures in a DSS has been developed in order to support policy makers to make a strategic selection between different measures while taking uncertainty into account. The methodology consists of an uncertainty analysis and a ranking procedure based on the significance of the difference between output distributions for different measures. These two steps are described below.

\subsection{Uncertainty analysis}

In an uncertainty analysis, the effect of different uncertainties (e.g. from data, models and parameters) on the output of interest (the decision variable) is determined. Two aspects are discussed, namely the type of uncertainty to be investigated and the choice of the uncertainty analysis method.

For illustrative purposes, only the effect of parameter uncertainty on the total flood damage is taken into account. This uncertainty source is chosen, because it may have large effects on the output, is relatively easy to quantify and is interesting in the context of the DSS. Only the uncertainty of six dominant parameters is considered. These are two parameters in the fast flow routine of the hydrological model, two parameters in the stage-discharge relation and one parameter in the inundation formulation of the hydraulic model, and one parameter in the flood damage function for rice of the socio-economic model. They have been selected on the basis of a first-order uncertainty analysis [see De Kort, 2003].

The uncertainty analysis method has been chosen based on a multi criteria analysis. Criteria for the selection were the nature of the model, research purpose, previous comparisons and available resources [Morgan and Henrion, 1990; Booij, 2002]. Based on this analysis, the Latin Hypercube Sampling (LHS) method has been chosen, which is a stratified sampling version of the Monte Carlo method and efficiently estimates the statistics of an output [Melching, 1995]. 


\subsection{Ranking procedure}

The ranking procedure is based on the significance of the difference between output distributions for different measures taking parameter uncertainty into account. Therefore, first the distribution type needs to be determined and second, the significance of the differences is required as described below.

The hypothesis of output distributions being normally distributed is tested visually with quantilequantile plots and quantitatively with the Kolmogorov-Smirnov test [see e.g. Zar, 1996]. The nature of the output distribution (Gaussian or nonGaussian) determines which test is used in the next step.

\section{RESULTS}

\subsection{Uncertainty analysis}
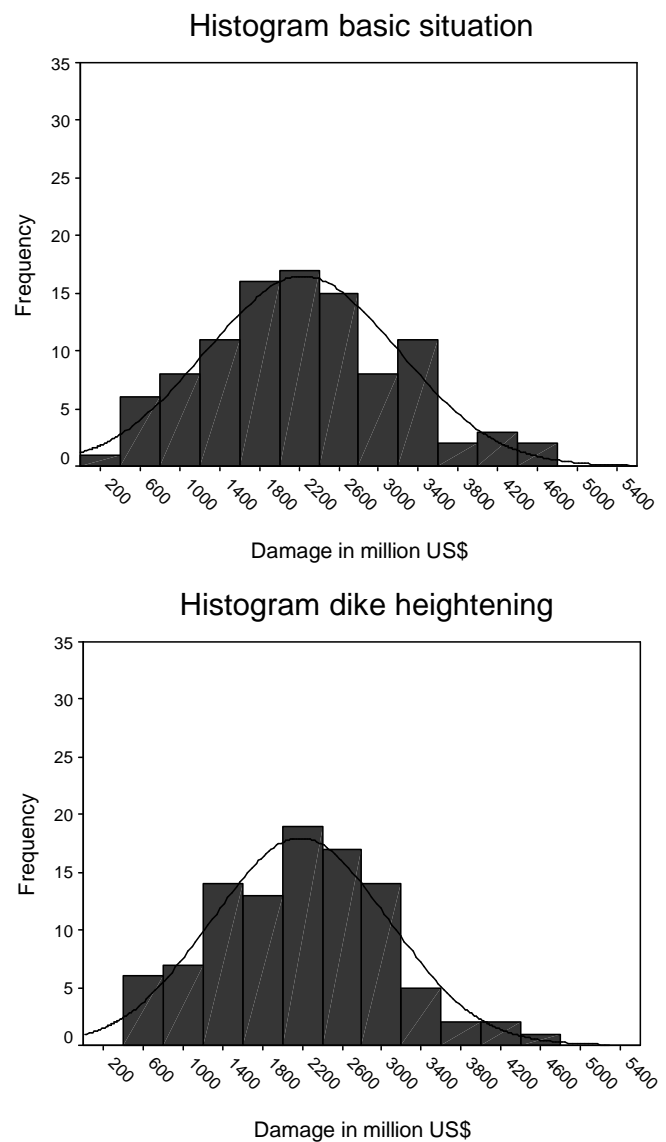

The significance is determined with the Student test for Gaussian distributions and with the Wilcoxon test for non-Gaussian distributions. The Student test compares the means of two distributions, while taking the variance of both distributions into account. The specific Student test to be used depends on the homogeneity of the variances from both distributions. The Wilcoxon signed rank test [see e.g. Zar, 1996], also known as the Mann-Whitney test, is a non-parametric test that detects differences in the distribution of two situations by ranking the output in both situations and comparing the resulting, standardised ranks.

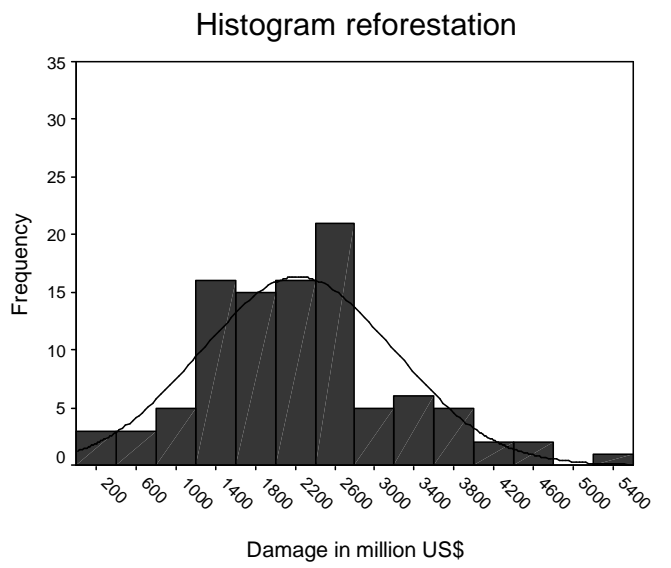

Histogram retention basin

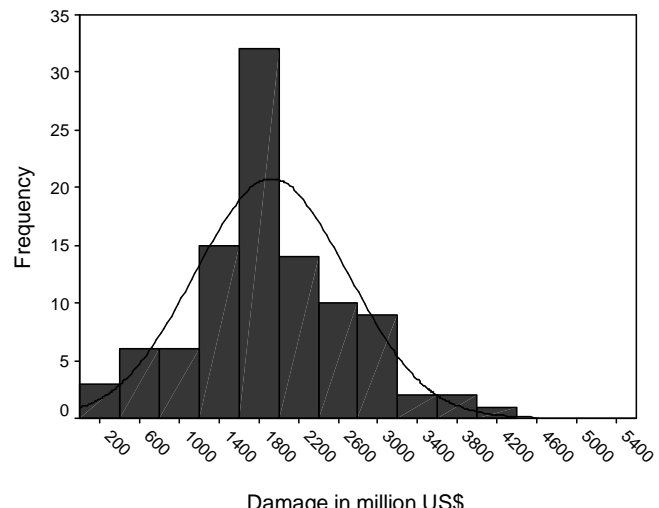

Figure 2. Histograms and fitted Gaussian curves for base situation and three flood control measures 
The results of the uncertainty analysis will be briefly described. First, some information about the dominant parameters and the implementation of LHS is given.

Only the six dominant parameters contributing considerably to the output uncertainty are sampled in the LHS uncertainty analysis. For all six parameters uniform distributions are assumed, because no data were available and other studies [e.g. Yu et al., 2001] employed uniform distributions for similar analyses as well. A total number of 100 samples of parameter sets has been used to generate 100 output values for each situation (base situation and three measures). This number of samples is arbitrary chosen based on previous uncertainty analysis studies and the fact that this number corresponds to a reasonable number of about 1000 samples when employing Monte Carlo analysis [Yu et al., 2001].

The results of the four sets of 100 LHS simulations are shown in Figure 2. The simulated mean flood damage for the base situation corresponds well with the observed one (not shown here) of about 2.2 billion US\$. It should be noted here that the flood of 1996 was one of the five major floods in the $20^{\text {th }}$ century and thus the resulting damage was high. The measures reforestation, dike heightening and the construction of a retention basin reduce the simulated mean flood damage with about 5, 55 and
300 million US\$ respectively. It should be noted that the extent to which the flood damage is reduced depends on the dimensions and the location of the flood control measure. The small effect of reforestation on the flood damage may be due to the fact that erosion and sedimentation processes are not taken into account in the DSS. These processes probably play an important role in realising the flood control function of reforestation. Standard deviations for all four situations are high (up to $45 \%$ of the mean value) indicating large uncertainties in the estimation of the total flood damage. Obviously, this results in large overlaps of the probability distributions shown in Figure 2.

\subsection{Ranking procedure}

The first step in the ranking procedure has been the determination of the distribution type. The quantilequantile plots showed reasonable straight lines with even in the tails only slight deviations from the expected normal value. This is confirmed quantitatively by the Kolmogorov-Smirnov test. Moreover, Large Lilliefors significance values (>> 0.05) indicated that the output results can be considered as normally distributed. The four normal distributions (gray line is under black line) and their statistical notation are shown in Figure 3.

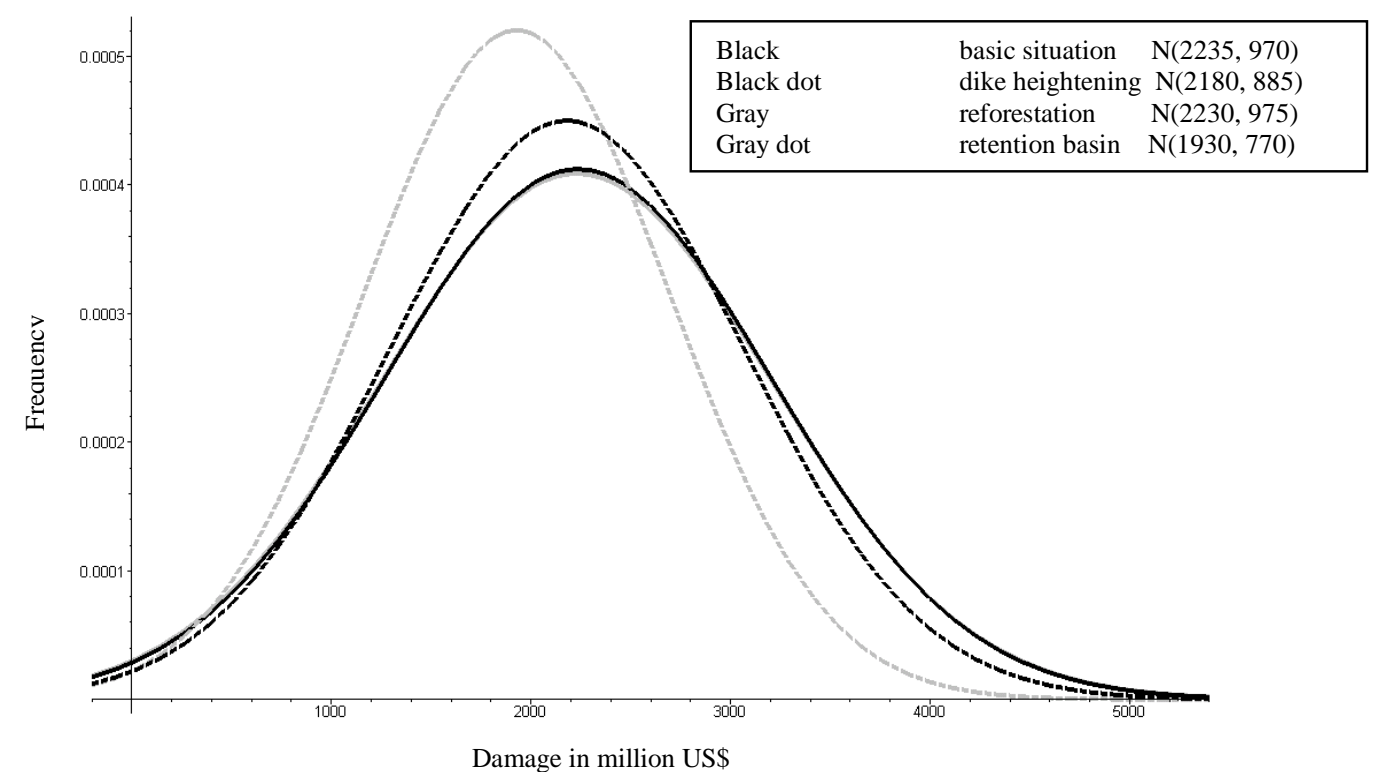

Figure 3. Normal distribution for base situation and three flood control measures (gray line is under black line). 
The second step has been the assessment of the significance of the difference between output distributions for different measures taking parameter uncertainty into account. The Student test is used for this purpose, because the model outputs were found to be normally distributed. According to this test, the construction of a retention basin is the only measure that significantly improves flood control for the Red River (two-tailed significance level $<0.05$ and a mean difference of about 300 million US\$). The other two flood control measures result in a smaller mean flood damage than in the base situation, but do not significantly improve the situation. The final ranking of the flood control measures is therefore: 1 . construction of a retention basin; 2 . dike heightening; 3. reforestation.

\section{CONCLUSIONS}

A methodology for the ranking of measures in a DSS while taking uncertainty into account has been developed and applied to a pilot DSS for flood control in the Red River basin in Vietnam and China. The methodology consists of an uncertainty analysis and a ranking procedure based on the significance of the difference between output distributions for different measures.

The mean flood damage in the base situation is about 2.2 billion US\$ for the year 1996 with a standard deviation due to parameter uncertainty of about 1 billion US\$. The measures reforestation, dike heightening and the construction of a retention basin reduce the flood damage with about 5, 55 and 300 million US\$ respectively. The construction of a retention basin significantly reduces flood damage in the Red River basin, while dike heightening and reforestation reduce flood damage, but not significantly.

Decision making on the basis of these results should be done with care. Several potentially important processes (e.g. erosion, sedimentation) are not taken into account yet, because of the pilot status of the DSS. Moreover, only six dominant parameters are considered in the uncertainty analysis. Other points which should be kept in mind are the dependency of the outcomes on the location and dimensions of the measures and the fact that implementation and maintenance costs of measures are not considered yet. However, the methodology proved to be suitable for the ranking of measures and may support decision makers when dealing with uncertainty.

\section{ACKNOWLEDGEMENTS}

This study has been done within the context of the FLOCODS project which is funded under the EC contract number ICA4-CT2001-10035 within the Fifth Framework Program. This study benefited greatly from the discussions with Denie Augustijn en Jean-Luc de Kok of the University of Twente.

\section{REFERENCES}

Bergström, S., and A. Forsman, Development of a conceptual deterministic rainfall-runoff model, Nordic Hydrology, 4, 147-170, 1973.

Booij, M.J., Appropriate modelling of climate change impacts on river flooding, Ph.D. thesis, University of Twente, Enschede, 2002.

Booij, M.J., Decision support system for flood control and ecosystem upgrading in Red River basin, In: G. Blöschl, S. Franks, M. Kumagai, K. Musiake and D. Rosbjerg (Eds.), Water Resources Systems - Hydrological Risk, Management and Development, Proc. Symposium HS02b at IUGG 2003, 30 June-11 July 2003, Sapporo, Japan, 115-122, 2003.

De Kort, I.A.T., Decision making under uncertaintyRanking measures in a decision support system for flood control in the Red River in Vietnam while taking uncertainty into account, M.Sc. thesis, University of Twente, Enschede, 2003.

Melching, C.S., Reliability estimation, In: V.P. Singh (Ed.), Computer models of watershed hydrology, Water Resources Publications, Colorado, 1995.

Morgan, M.G., and M. Henrion, Uncertainty: a guide to dealing with uncertainty in quantitative risk and policy analysis, Cambridge University Press, Cambridge, 1990

Nghia, T., Flood control planning for Red River basin, Proceedings of International EuropeanAsian Workshop Ecosystem \& Flood, Hanoi, Vietnam, 2000.

Wesseling, C.G., D.-J. Karssenberg, P.A. Burrough, and W.P.A. van Deurssen, Integrating dynamic environmental models in GIS: the development of a dynamical modelling language, Transactions in GIS, 1, 40-48, 1996.

Yu, P.-S., T.-C. Yang, and S.-J. Chen, Comparison of uncertainty analysis methods for a distributed rainfall-runoff model, Journal of Hydrology, 244, 43-59, 2001.

Zar, J.H., Biostatistical analysis, Prentice Hall, Upper Saddle River, NJ, 1996. 